\title{
Paraquat toxicity is reduced by nitric oxide in rice leaves
}

\author{
Kuo Tung Hung, Chin Jung Chang, Ching Huei Kao* \\ Department of Agronomy, National Taiwan University, Taipei, Taiwan, Republic of China
}

Received July 2, 2001 · Accepted October 1, 2001

\section{Summary}

The role of nitric oxide (NO) in plants has been the object of intensive research. In the present work, we evaluated the protective effect of $\mathrm{NO}$ against paraquat $(\mathrm{PQ})$ toxicity of rice (Oryza sativa) leaves. $P Q$ toxicity in rice leaves was determined by the decrease of protein content. $P Q$ toxicity of rice leaves was reduced by free radical scavengers such as thiourea, sodium benzoate, ascorbic acid and sodium azide. NO-releasing compounds [N-tert-butyl- $\alpha$-phenylnitrone (PBN), sodium nitroprusside (SNP), 3-morpholinosydnonimine ( $\mathrm{SIN}-1$ ), and ascorbic acid $+\mathrm{NaNO}_{2}$ ] were effective in reducing $P Q$ toxicity in rice leaves. SIN-1 and ascorbic acid $+\mathrm{NaNO}_{2}$ prevented both the $\mathrm{PQ}$-induced increase in content of malondialdehyde and the PQ-induced decrease in activities of active oxygen species-detoxifying enzymes. The protective effect of SIN-1 or ascorbic acid $+\mathrm{NaNO}_{2}$ on $\mathrm{PQ}$ toxicity, $P Q$-induced lipid peroxidation and $P Q$-decreased antioxidative enzyme activities was reversed by 2-(4-carboxy-2-phenyl)-4,4,5,5-tetramethylimidazoline-1-oxyl-3-oxide, a NO-specific scavenger, suggesting that the protective effect of NO-releasing compounds is attributed to NO released. Reduction of $P Q$ toxicity by $N O$ in rice leaves is most likely mediated through increase in antioxidative enzyme activities and decrease in lipid peroxidation.

Key words: lipid peroxidation - nitric oxide - Oryza sativa - paraquat

Abbreviations: Asc ascorbate. - APOD ascorbate peroxidase. - CAT catalase. - c-PTIO 2-(4-carboxy-2-phenyl)-4,4,5,5-tetramethylimidazoline-1-oxyl-3-oxide. - GR glutathione reductase. - MDA malondialdehyde. - NO nitric oxide. - PBN N-tert-butyl- $\alpha$-phenylnitrone. - POD peroxidase. - PQ paraquat. - SIN-1 3-morpholinosydonimine. - SNP sodium nitroprusside. - SA sodium azide. - SB sodium benzoate. - SOD superoxide dismutase

\section{Introduction}

Paraquat (PQ), also known as methyl viologen, is a herbicide widely used in agriculture. It has long been known to exert its toxic effects by catalyzing the transfer of electrons from pho-

* E-mail corresponding author: kaoch@ccms.ntu.edu.tw tosystem I of chloroplast membrane to molecular oxygen, producing oxygen radicals that cause lipid peroxidation and membrane damage (Calderbank 1968, Farrington et al. 1973, Cha et al. 1982). A normally operated photosynthetic electron transport is usually required for inducing $P Q$ toxicity (Mees 1960, Chang and Kao 1995). Superoxide can serve as a source to generate more active hydroxyl radicals by Haber- 
Weiss and Fenton reactions (Naqui and Chance 1986). Transition metals, such as iron and copper, are able to accelerate Haber-Weiss and Fenton reactions (Gutteridge et al. 1981). It has been demonstrated that iron or copper ions are essential mediators in $\mathrm{PQ}$ toxicity in bacterial cells (Kohen and Chevion 1985), in mammalian cells in tissue culture (Sandy et al. 1987) and mice (Kohen and Chevion 1986). It has been shown that $P Q$ toxicity in pea and rice leaves is enhanced by iron and reduced by iron chelators (Zer et al. 1994, Chang and Kao 1997 a). Free radical scavenging properties of polyamines have been documented (Drolet et al. 1986). It was found that polyamines were effective in reducing $P Q$ toxicity of rice and sunflower leaves (Chang and Kao 1997b, Benavides et al. 2000).

Nitric oxide (NO) is a labile free radical and is produced from L-arginine by NO synthase in mammalian cells (Sakuma et al. 1988, Rees et al. 1989). Over the last decade, extensive research about the role of NO in animals has demonstrated that it is a key signal molecule involved in a wide variety of processes including vasorelaxation, neurotransmission, and the innate immune response (Schmidt and Walter 1994). In contrast, the role of NO in plants is less well understood. Evidence is emerging to support that NO may also play some roles in the plant kingdom. Antibodies raised against rabbit NO synthase cross-reacted with proteins from pea embryonic axes and wheat germ (Sen and Cheema 1995). In senescing pea leaves, NO emission was promoted by the addition of ethylene precursors and NO-releasing compounds inhibited leaf expansion (Leshem and Haramaty 1996). Leshem et al. (1998) provided evidence to show that NO is a natural senescence-delaying plant growth regulating agent. NO-releasing compounds were found to promote phytoalexin accumulation in potato tuber tissues (Noritake et al. 1996), inhibit coniferyl alcohol peroxidase activity in the xylem of Zinnia elegans (Ferrer and Bacelo 1999), inhibit cytochrome oxidase activity in isolated soybean cotyledon mitochondria (Millar and Day 1996), and inhibit the activity of tobacco aconitase, catalase (CAT), ascorbate peroxidase (APOD) and salicylic acidinduced protein kinase (Clark et al. 2000, Kumar and Klessig 2000, Navarre et al. 2000). The participation of NO as a signal in plant disease resistance has also been reported (Delledonne et al. 1998, Durner et al. 1998, Klessig et al. 2000). Scherer and Holk (2000) also observed that NO could be an intermediate in cytokinin signaling.

Since NO is a toxic free radical, most of the work on NO function in plant cells has focused on its ability to act in the same direction as active oxygen species. In animal systems, several reports convincingly demonstrate a protective role for NO in oxidative stress (Rubbo et al. 1984, Wink et al. 1993, Rauhala et al. 1996, Goss et al. 1997, O'Donnell et al. 1997, d'Ischia et al. 2000). In a series of work conducted by Lamattina's group, it was found that NO protects against cellular damage produced by diquat, $\mathrm{PQ}$ and Phytophthora infestans in potato leaves (Laxalt et al. 1997, Beligni and Lamattina $1999 \mathrm{a}, \mathrm{b})$. It is not known whether a similar protective role for
$\mathrm{NO}$ is also active in other leaf systems. For this reason, we investigated the effect of $\mathrm{NO}$ on the toxicity of $\mathrm{PQ}$, a well known free-radical generating chemical, in rice leaves.

\section{Materials and Methods}

\section{Materials and chemicals}

Rice (Oryza sativa L., cv. Taichung Native 1) was cultured as previously described (Lin et al. 1999). The apical 3-cm segments excised from the third leaves of 12-day-old seedlings were used. A group of 10 segments was floated in a Petri dish containing $10 \mathrm{~mL}$ of test solution. Incubation was carried out at $27^{\circ} \mathrm{C}$ in the light $\left(40 \mu \mathrm{mol} \mathrm{m}^{-2} \mathrm{~s}^{-1}\right)$.

Test solutions included PQ, NO-releasing compounds, a NO scavenger (c-PTIO), and antioxidant compounds. PBN, SIN-1 and SNP were used as NO-releasing compounds. We also used a solution containing ascorbic acid (Asc) and $\mathrm{NaNO}_{2}$ as another NO-releasing compound. Asc, sodium azide (SA), sodium benzoate (SB), and thiourea were used as antioxidants. All chemicals were purchased from Sigma Co. (St. Louis, MO, USA).

\section{Chlorophyll, protein and MDA determinations}

Chlorophyll was determined according to Wintermans and De Mots (1965) after extraction in 96\% (v/v) ethanol. For protein extraction, leaf segments were homogenized in $50 \mathrm{mmol} \mathrm{L}^{-1}$ sodium phosphate buffer $(\mathrm{pH}$ 6.8). The extracts were centrifuged at $17,000 \times \mathrm{g}$ for $20 \mathrm{~min}$, and the supernatants were used for determination of both protein by the method of Bradford (1976) and enzyme activities. Malondialdehyde (MDA) was extracted with $5 \%(\mathrm{w} / \mathrm{v})$ trichloroacetic acid and determined according to Heath and Packer (1968).

\section{Enzyme assays}

Peroxidase (POD) activity was measured using a modification of the procedure of MacAdam et al. (1992). Activity was calculated using the extinction coefficient [26.6 (mmol L $\left.{ }^{-1}\right)^{-1} \mathrm{~cm}^{-1}$ at $470 \mathrm{~nm}$ ] for tetraguaiacol. CAT activity was assayed by measuring the initial rate of disappearance of $\mathrm{H}_{2} \mathrm{O}_{2}$ (Kato and Shimizu 1987). The decrease in $\mathrm{H}_{2} \mathrm{O}_{2}$ was followed as the decline in absorbance at $240 \mathrm{~nm}$, and activity was calculated using the extinction coefficient $\left[40\left(\mathrm{mmol} \mathrm{L}^{-1}\right)^{-1} \mathrm{~cm}^{-1}\right.$ at $240 \mathrm{~nm}$ ] for $\mathrm{H}_{2} \mathrm{O}_{2}$ (Kato and Shimizu 1987). Superoxide dismutase (SOD) was determined according to Paoletti et al. (1986). APOD was determined according to Nakano and Asada (1981). The decrease in Asc concentration was followed as the decline in optical density at $290 \mathrm{~nm}$ and activity was calculated using the extinction coefficient [2.8 $\left(\mathrm{mmol} \mathrm{L}^{-1}\right)^{-1} \mathrm{~cm}^{-1}$ at $290 \mathrm{~nm}$ ] for Asc. Glutathione reductase (GR) was determined by the method of Foster and Hess (1980). One unit of activity for CAT, POD, SOD, APOD, and GR was defined as the amount of enzyme which degraded $1 \mu \mathrm{mol} \mathrm{H}_{2} \mathrm{O}_{2}$ per min, caused the formation of $1 \mu \mathrm{mol}$ tetraguaiacol per min, inhibited $50 \%$ the rate of $\mathrm{NADH}$ oxidation observed in control, degraded $1 \mu \mathrm{mol}$ of Asc per min, and decreased $1 \mathrm{~A}_{340}$ per min, respectively.

\section{Experimental design}

Protein and MDA contents were expressed per $g$ fresh weight (FW). Enzyme activities were expressed as units $\mathrm{g}^{-1} \mathrm{FW}$ or units $\mathrm{mg}^{-1}$ pro- 
tein. Absolute contents of each measurement varied among experiments because of seasonal effects. However, the patterns of responses to $P Q, P Q$ plus NO-releasing compounds or $P Q$ plus antioxidants were reproducible. For biochemical analysis, four independent extractions were performed for each treatment. All experiments described here were repeated at least three times. Similar results and identical trends were obtained each time. The data reported here are from a single experiment.

\section{Results and Discussion}

Changes in chlorophyll, protein, and MDA contents in detached rice leaves treated with $25 \mu \mathrm{mol} \mathrm{L}^{-1} \mathrm{PQ}$ in the light are shown in Figure 1. The decrease in protein and increase in
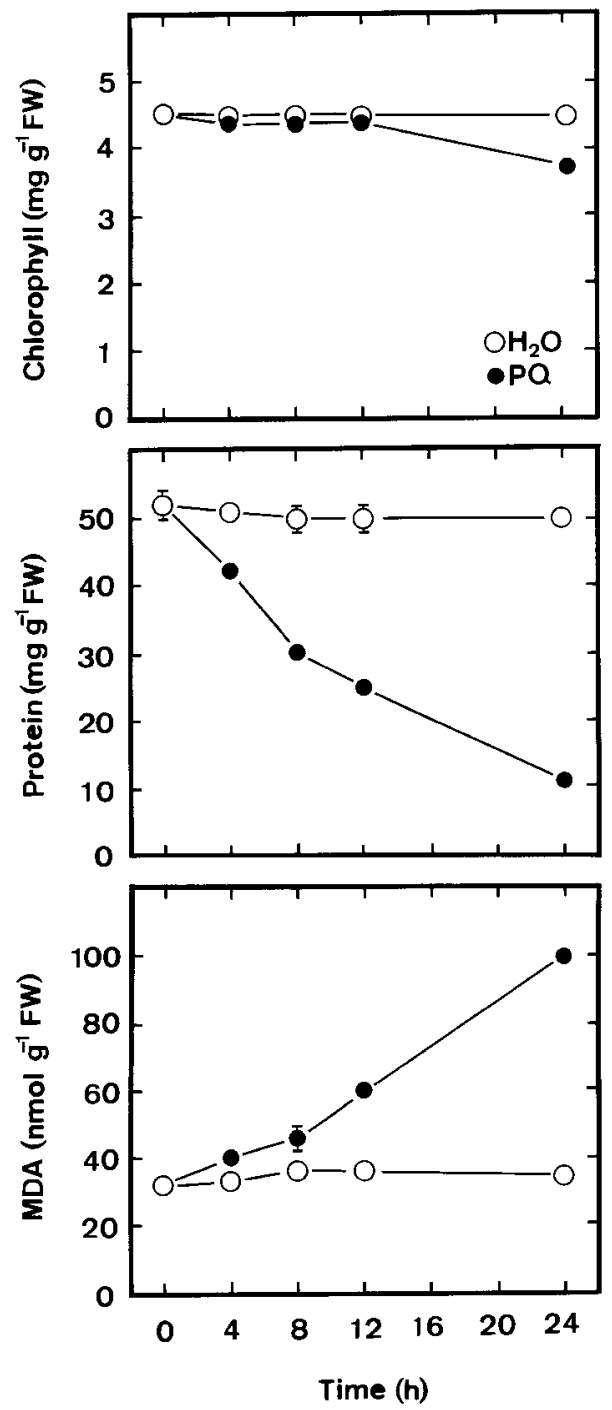

Figure 1. Changes in contents of chlorophyll, protein and MDA in rice leaves treated with $P Q$. Detached rice leaves were treated with either water or $25 \mu \mathrm{mol} \mathrm{L}{ }^{-1} \mathrm{PQ}$ in the light. Vertical bars represent standard errors $(n=4)$. Only those standard errors larger than the symbol are shown.

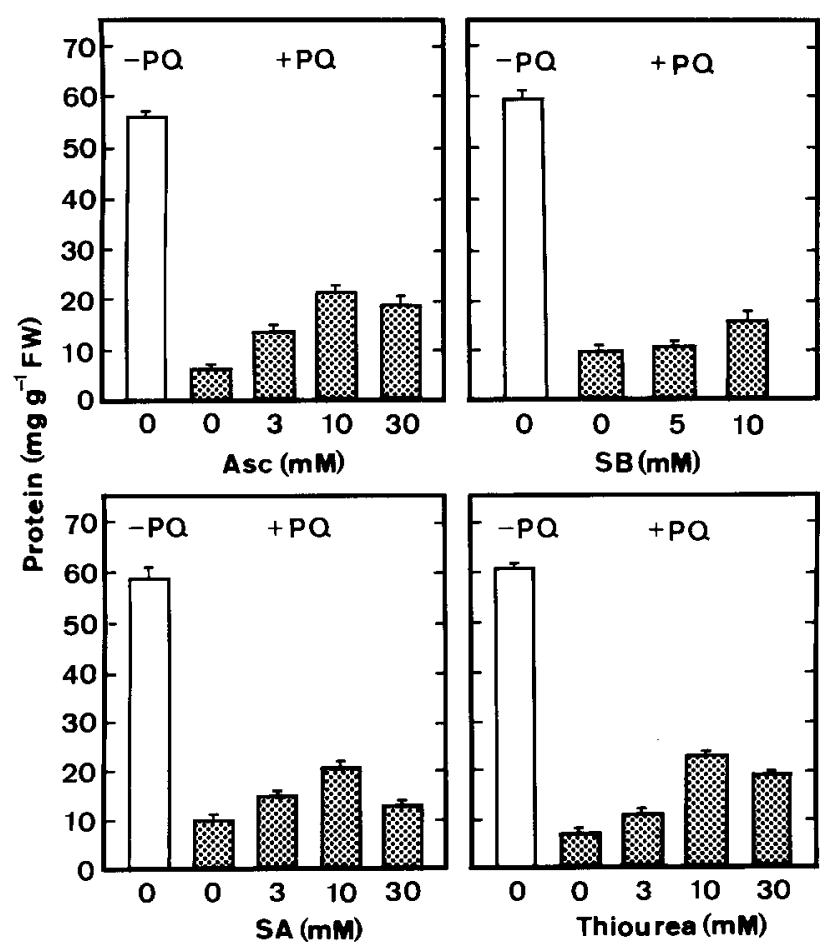

Figure 2. Effect of antioxidants (Asc, SB, SA, and thiourea) on protein content in rice leaves treated with $P Q$. The concentration of $P Q$ was $25 \mu \mathrm{mol} \mathrm{L}^{-1}$. Protein was determined $24 \mathrm{~h}$ after treatment in the light. The white columns mean that detached rice leaves were treated with water only. Vertical bars represent standard errors $(n=4)$.

MDA were evident at $4 \mathrm{~h}$ after $\mathrm{PQ}$ treatment. However, slight decrease in chlorophyll was only observed at $24 \mathrm{~h}$ after $\mathrm{PQ}$ treatment. Clearly, $P Q$ is more effective in decreasing protein content than chlorophyll content. Thus, $P Q$ toxicity in detached rice leaves was judged by the decrease in protein content in the following experiments. It is generally believed that the primary action of $P Q$ is a result of the deviation of photosynthetic electron transport in chloroplasts (Calderbank 1968). Previously, we demonstrated that considerable reduction of $P Q$ toxicity in rice leaves occurred in the presence of photosynthetic electron transport inhibitors in the light and that $P Q$ was unable to induce toxicity in detached rice leaves under dark condition (Chang and Kao 1995). These results suggest that light is essential for $P Q$ response in rice leaves, although the light intensity $\left(40 \mu \mathrm{mol} \mathrm{m}^{-2} \mathrm{~s}^{-1}\right)$ used in the present investigation is quite low compared to sunlight. It appears that detached rice leaves are highly sensitive to $P Q$.

$P Q$ treatment resulted in a marked increase in MDA content, indicating that $P Q$ brings about lipid peroxidation (Fig. 1). Lipid peroxidation is caused by active oxygen species (Foster and Hess 1980). Free radical scavenging properties of polyamines have been documented (Drolet et al. 1986) and it was found that polyamines were effective in reducing $P Q$ toxicity of rice leaves (Chang and Kao 1997b). Transition met- 
als, such as iron and copper, are able to accelerate HaberWeiss and Fenton reactions (Gutteridge et al. 1981). Evidence was also provided to show that $P Q$ toxicity was reduced by iron chelators in rice leaves (Chang and Kao 1997a). These results support the possibility that $P Q$-induced toxicity in rice leaves is mediated through oxidative stress. In the present investigation, when free radical scavengers such as thiourea, $\mathrm{SB}, \mathrm{SA}$ and Asc were used together with $\mathrm{PQ}$, it was found that they partially prevented the toxicity of $P Q$ in rice leaves (Fig. 2). However, Asc, SB, SA, and thiourea alone had no effect on protein content (data not shown). These results support the involvement of free radicals as the chemical species inducing $P Q$ toxicity in rice leaves.

Beligni and Lamattina (1999a,b) reported that NO counteracts cellular damage caused by diquat in potato leaves. Based on their evidence, they propose that $\mathrm{NO}$ acts as an antioxidant in reducing cellular damage. Thus, it is of great interest to know whether a similar protective role of NO is also active in the rice leaf system. Consequently, detached rice leaves were treated with $P Q$ in the presence or absence of NO-releasing compounds, such as PBN, SIN-1, SNP and a mixture Asc and $\mathrm{NaNO}_{2}$ for $24 \mathrm{~h}$ in the light. As indicated in Table 1, all NO-releasing compounds used are effective in reducing $P Q$ toxicity in rice leaves. We also observed that $100 \mu \mathrm{mol} \mathrm{L}^{-1}$ SIN-1 and $100 \mu \mathrm{mol} \mathrm{L}^{-1}$ Asc plus $200 \mu \mathrm{mol} \mathrm{L}^{-1}$ $\mathrm{NaNO}_{2}$ are more effective in reducing $P Q$ toxicity than PBN and SNP.

SIN-1 alone had no effect on protein content (Fig. 3). When applied together with $\mathrm{PQ}, \mathrm{SIN}-1$ concentrations between 50 and $200 \mu \mathrm{mol} \mathrm{L}^{-1}$ produced a clear protection against protein loss (Fig. 3). The optimal concentration of SIN-1 in reducing $\mathrm{PQ}$ toxicity was observed to be $100 \mu \mathrm{mol} \mathrm{L}^{-1}$. It was also observed that $\mathrm{NaNO}_{2}$ alone (Fig. $4 \mathrm{~A}$ ) or Asc alone (Fig. 4B) had no effect on protein content in detached rice leaves. Both Asc and $\mathrm{NaNO}_{2}$ are required in reducing $\mathrm{PQ}$ toxicity of detached rice leaves (Figs. $4 \mathrm{~A}$ and $4 \mathrm{~B}$ ). To be effective in reducing $\mathrm{PQ}$ toxicity, the optimal concentrations of $A s c$ and $\mathrm{NaNO}_{2}$ were

Table 1. Effect of NO-releasing compounds on protein content in rice leaves treated with $\mathrm{PQ}$

\begin{tabular}{lc}
\hline Treatment & Protein, $\mathrm{mg} \mathrm{g}^{-1} \mathrm{FW}$ \\
\hline $\mathrm{H}_{2} \mathrm{O}$ & $53.6 \pm 1.0$ \\
$\mathrm{PQ}$ & $8.7 \pm 0.6$ \\
$\mathrm{PQ}+\mathrm{PBN}$ & $17.1 \pm 1.5$ \\
$\mathrm{PQ}+\mathrm{SIN}-1$ & $20.2 \pm 1.7$ \\
$\mathrm{PQ}+\mathrm{SNP}$ & $16.1 \pm 1.3$ \\
$\mathrm{PQ}+\mathrm{AsC}+\mathrm{NaNO}_{2}$ & $22.9 \pm 1.9$ \\
\hline
\end{tabular}

The concentrations of PQ, PBN, SIN-1, SNP, Asc, and $\mathrm{NaNO}_{2}$ were 25, $100,100,100,100$, and $200 \mu \mathrm{mol} \mathrm{L}^{-1}$, respectively. Protein content was determined $24 \mathrm{~h}$ after treatment in the light, data are the means \pm standard errors $(n=4)$.

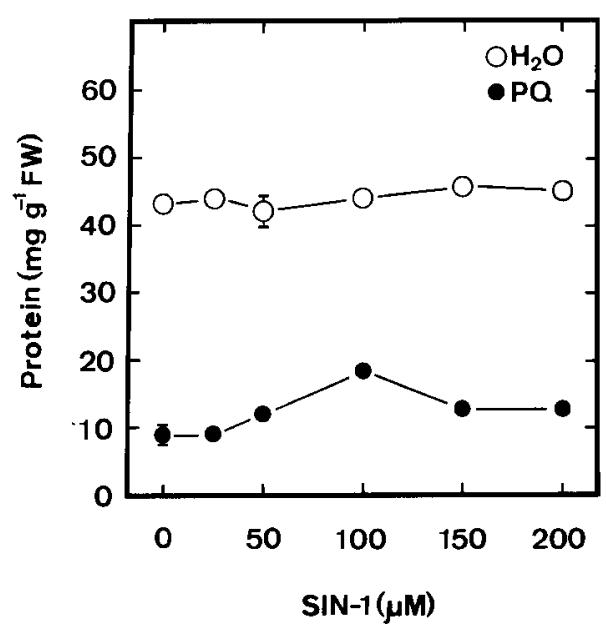

Figure 3. Effect of SIN-1 concentrations on protein contents in rice leaves treated with either water or $P Q$. The concentration of $P Q$ was $25 \mu \mathrm{mol} \mathrm{L}^{-1}$. Protein was determined $24 \mathrm{~h}$ after treatment in the light. Vertical bars represent standard errors $(n=4)$. Only those standard errors larger than the symbol are shown.

100 and $200 \mu \mathrm{molL}^{-1}$, respectively (Figs. $4 \mathrm{~A}$ and $4 \mathrm{~B}$ ). The protective effect of SIN-1 or Asc $+\mathrm{NaNO}_{2}$ on $\mathrm{PQ}$ toxicity was observed to be evident at $4 \mathrm{~h}$ after treatment (data not shown).

To investigate whether the protective effect induced by treatment with NO-releasing compounds ( $\mathrm{SIN}-1$ and Asc + $\mathrm{NaNO}_{2}$ ) was the result of the production of $\mathrm{NO}, 100 \mu \mathrm{mol} \mathrm{L}^{-1}$ c-PTIO, a NO-specific scavenger, was applied along with $100 \mu \mathrm{mol} \mathrm{L}^{-1} \mathrm{SIN}-1$ or $100 \mu \mathrm{mol} \mathrm{L}^{-1}$ Asc $+200 \mu \mathrm{mol} \mathrm{L}^{-1} \mathrm{NaNO}_{2}$. The protective effect of $\mathrm{SIN}-1$ or Asc $+\mathrm{NaNO}_{2}$ on $\mathrm{PQ}$-induced toxicity could be reversed by c-PTIO (Fig. 5). Clearly, the protective effect on $\mathrm{PQ}$ toxicity by NO-releasing compounds is due to NO.

The addition of $\mathrm{NO}$ to rat brain homogenates caused a decrease in lipid peroxidation (d'Ischia et al. 2000). PQ induces lipid peroxidation in several leaf systems (Calderbank 1968, Farrington et al. 1973, Cha et al. 1982, Chang and Kao 1997a). Until now it was not known whether NO-releasing compounds can confer protection against lipid peroxidation in plant systems. Figure 6 shows the effect of $\mathrm{SIN}-1$ and $\mathrm{Asc}+\mathrm{NaNO}_{2}$ on MDA content of detached rice leaves treated with $P Q$. $P Q$ alone resulted in a marked increase in MDA content (Figs. 1 and 6). Although $\mathrm{SIN}-1$ or Asc $+\mathrm{NaNO}_{2}$ alone had no effect on MDA content (data not shown), treatment with SIN-1 or Asc $+\mathrm{NaNO}_{2}$ caused a reduction of $\mathrm{PQ}$-induced increase in MDA content (Fig. 6). The effect of $\mathrm{SIN}-1$ or Asc $+\mathrm{NaNO}_{2}$ on PQinduced MDA content could also be reversed by c-PTIO (Fig.6).

The protective effect of NO-releasing compounds on $P Q$ toxicity is clearly associated with the decrease in lipid peroxidation (Fig. 6) and protein loss (Fig. 5). Plant cells are equipped with several free radical detoxifying enzymes to protect them against oxidative damage. These enzymes in- 
Figure 4. (A) Effect of $\mathrm{NaNO}_{2}$ concentrations on protein content of rice leaves treated with water or $25 \mu \mathrm{mol} \mathrm{L}^{-1} \mathrm{PQ}+100 \mu \mathrm{mol} \mathrm{L}-1$ Asc; (B) Effect of Asc concentrations on protein content in rice leaves treated with water or $25 \mu \mathrm{mol} \mathrm{L}-1 \mathrm{PQ}+$ $200 \mu \mathrm{mol} \mathrm{L}^{-1} \mathrm{NaNO}_{2}$. Protein was determined $24 \mathrm{~h}$ after treatment in the light. Vertical bars represent standard errors $(n=4)$. Only those standard errors larger than the symbol are shown.

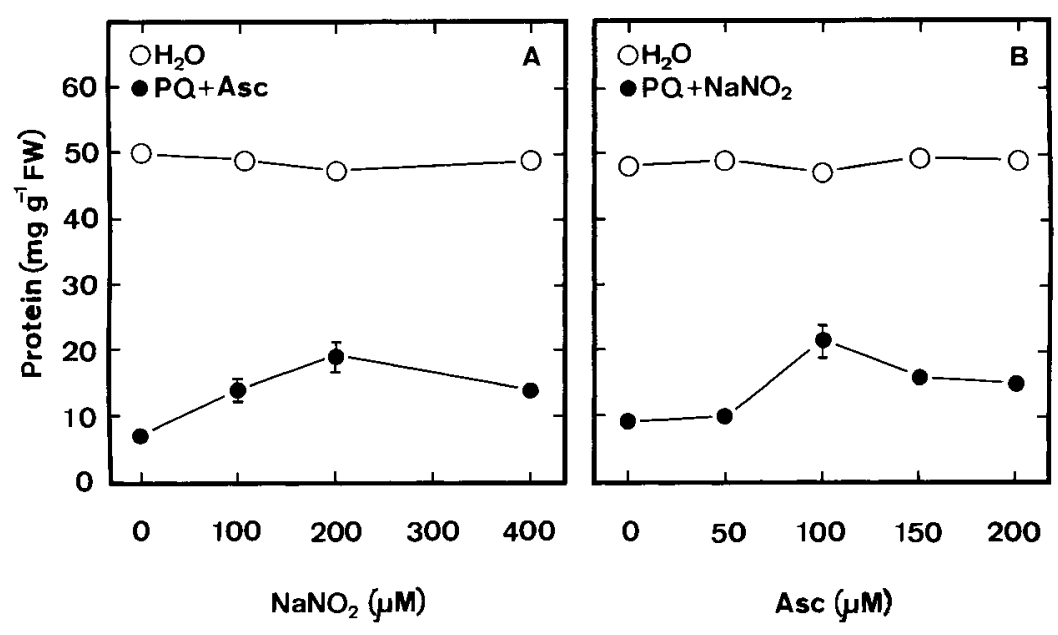

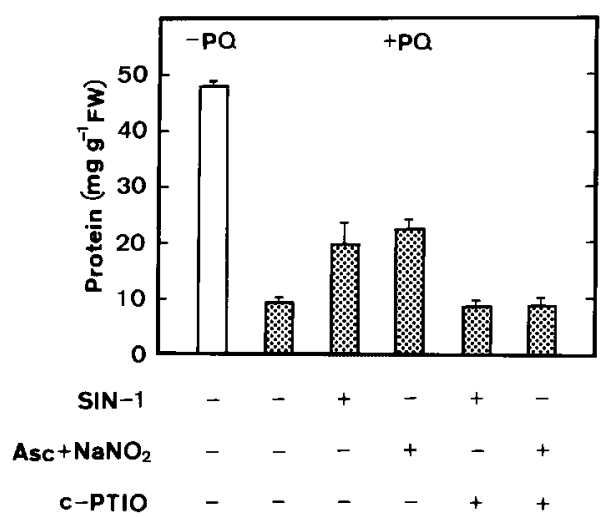

Figure 5. Effect of $\mathrm{SIN}-1$ and $\mathrm{Asc}+\mathrm{NaNO}_{2}$ on $\mathrm{PQ}$ toxicity in rice leaves in the presence $(+)$ or absence $(-)$ of c-PTIO. The concentrations of SIN-1, Asc, $\mathrm{NaNO}_{2}, \mathrm{PQ}$, and c-PTIO were 100, 100, 200, 25, and $100 \mu \mathrm{mol} \mathrm{L}^{-1}$, respectively. Protein was determined $24 \mathrm{~h}$ after treatment in the light. The white columns mean that detached rice leaves were treated with water only. Vertical bars represent standard errors $(n=4)$. clude SOD, APOD, GR, CAT and POD (Foyer et al. 1997, Nakano and Asada 1981). The striking changes in lipid peroxidation seen in leaves treated with $P Q$ alone may be a reflection of the inability of the scavenging enzymes to cope with the increased levels of oxidant species and/or their degradation by these species. Treatment with $P Q$ alone decreases POD, CAT, SOD, APOD and GR activities (Fig. 6). The PQ-induced loss of antioxidative enzyme activities was found to be protected by $\mathrm{SIN}-1$ or Asc $+\mathrm{NaNO}_{2}$ (Fig. 6). Treatment with c-PTIO alone was found to have no effect on MDA content and antioxidative enzyme activities (data not shown). However, c-PTIO arrested NO-releasing compounds-mediated enzyme protection (Fig. 6 ). It should be noted that when antioxidative enzymes were expressed as specific activities (units $\mathrm{mg}^{-1}$ protein), $\mathrm{PQ}$ increased specific activities of antioxidative enzymes, NOreleasing compounds counteracted PQ-increased specific activities of antioxidative enzymes and C-PTIO reversed the effect of NO-releasing compounds-mediated enzyme protection ( $\mathrm{Ta}$ ble2).

Ferrer and Barcelo (1999) found that the NO donor SNP $\left(5 \mathrm{mmol} \mathrm{L}^{-1}\right)$ and $\mathrm{NO}\left(55 \mu \mathrm{mol} \mathrm{L}^{-1} \mathrm{~s}^{-1}\right)$ itself were able to inhibit

Table 2. Effect of SIN-1 and Asc $+\mathrm{NaNO}_{2}$ on the specific activities of antioxidative enzymes in PQ-treated rice leaves in the presence or absence of C-PTIO.

\begin{tabular}{|c|c|c|c|c|c|c|}
\hline \multirow[b]{2}{*}{ Units $\mathrm{mg}^{-1}$ protein } & \multicolumn{6}{|c|}{ Treatment } \\
\hline & $\mathrm{H}_{2} \mathrm{O}$ & $P Q$ & $P Q+S I N-1$ & $\begin{array}{l}\mathrm{PQ}+\mathrm{Asc} \\
+\mathrm{NaNO}_{2}\end{array}$ & $\begin{array}{l}\mathrm{PQ}+\mathrm{SIN}-1 \\
+\mathrm{c}-\mathrm{PTIO}\end{array}$ & $\begin{array}{l}\mathrm{PQ}+\mathrm{Asc}+ \\
\mathrm{NaNO}_{2}+\mathrm{c}-\mathrm{PTIO}\end{array}$ \\
\hline CAT & $0.11 \pm 0.01$ & $0.23 \pm 0.02$ & $0.16 \pm 0.03$ & $0.18 \pm 0.01$ & $0.24 \pm 0.01$ & $0.24 \pm 0.02$ \\
\hline POD & $0.68 \pm 0.02$ & $2.25 \pm 0.17$ & $1.71 \pm 0.16$ & $1.80 \pm 0.22$ & $3.44 \pm 0.22$ & $3.60 \pm 0.44$ \\
\hline SOD & $1.01 \pm 0.03$ & $4.03 \pm 0.16$ & $2.11 \pm 0.05$ & $1.28 \pm 0.09$ & $4.51 \pm 0.19$ & $4.35 \pm 0.15$ \\
\hline APOD & $0.77 \pm 0.01$ & $1.56 \pm 0.08$ & $1.21 \pm 0.16$ & $1.17 \pm 0.07$ & $1.95 \pm 0.15$ & $2.19 \pm 0.23$ \\
\hline GR & $0.18 \pm 0.02$ & $0.60 \pm 0.05$ & $0.44 \pm 0.07$ & $0.42 \pm 0.03$ & $0.94 \pm 0.09$ & $1.03 \pm 0.15$ \\
\hline
\end{tabular}

The concentrations of $\mathrm{PQ}, \mathrm{SIN}-1, \mathrm{Asc}$, and $\mathrm{NaNO}_{2}$ were $25,100,100$, and $200 \mu \mathrm{mol} \mathrm{L}^{-1}$, respectively. Enzyme specific activities were determined $24 \mathrm{~h}$ after treatment in the light, data are the means \pm standard errors $(n=4)$. 

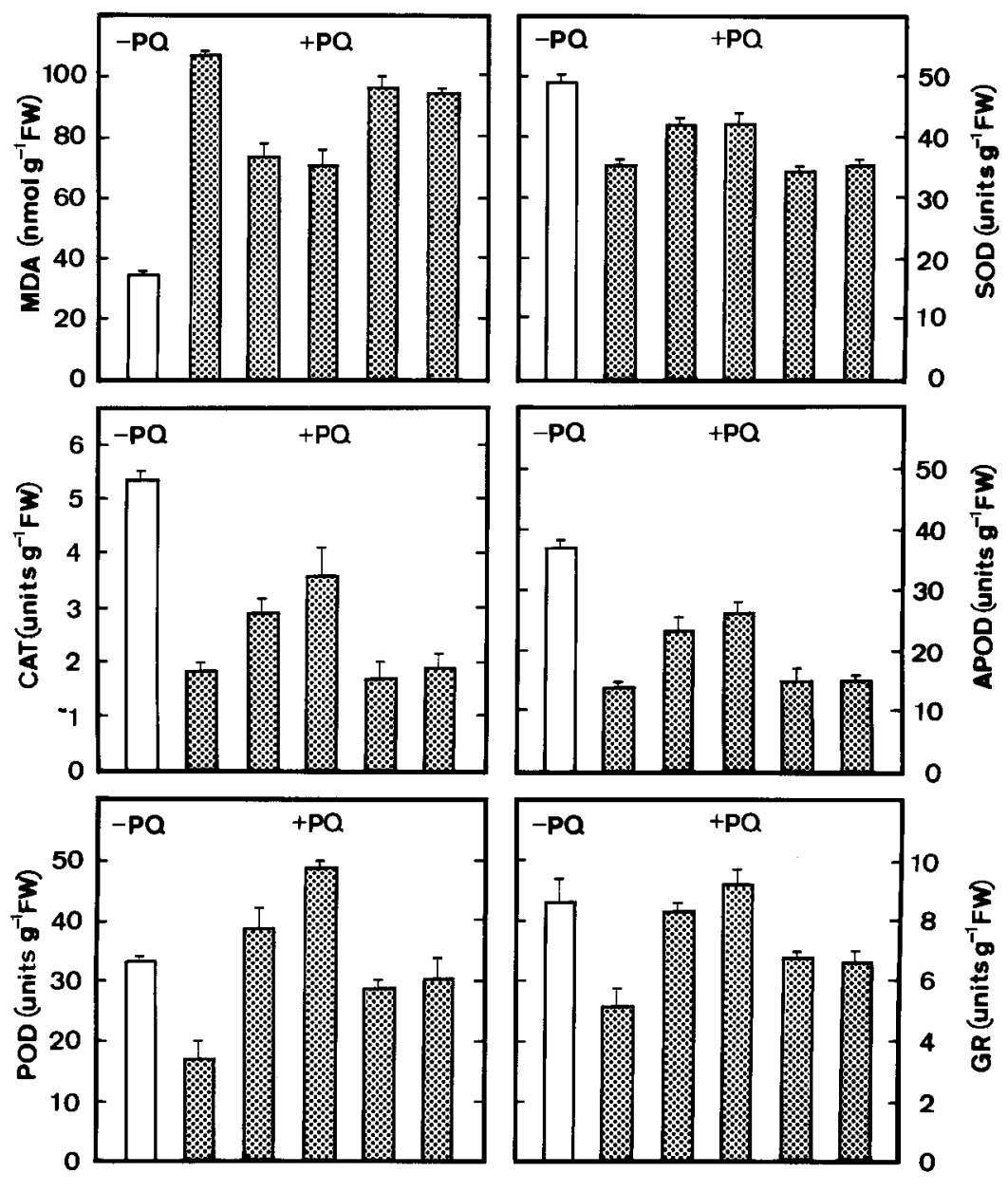

Figure 6. Effect of $\mathrm{SIN}-1$ and $\mathrm{Asc}+\mathrm{NaNO}_{2}$ on the content of MDA and the activities of antioxidative enzymes in $P Q$-treated rice leaves in the presence $(+)$ or absence $(-)$ of c-PTIO. The concentrations of SIN -1 , Asc, $\mathrm{NaNO}_{2}, \mathrm{PQ}$, and c-PTIO were 100 , $100,200,25$, and $100 \mu \mathrm{mol} \mathrm{L}^{-1}$, respectively. MDA content and enzyme activities were determined $24 \mathrm{~h}$ after treatment in the light. The white columns mean that detached rice leaves were treated with water only. Vertical bars represent standard errors $(n=4)$.

POD activity in the xylem of Zinnia elegans. Clark et al. (2000) also demonstrated that $\mathrm{NO}$ donor $\left(0.8 \mathrm{mmol} \mathrm{L}^{-1}\right)$ inhibited the activities of tobacco CAT and APOD, heme-containing enzymes. However, our results show that neither SIN-1 nor Asc + $\mathrm{NaNO}_{2}$ treatment effected the activities of POD, CAT, and APOD in rice leaves (data not shown). Why is SIN-1 or Asc + $\mathrm{NaNO}_{2}$ able to counteract $\mathrm{PQ}$ toxicity, but not able to inhibit the activities of POD, CAT, and APOD in rice leaves? In the present investigation, we used $\mu \mathrm{mol} \mathrm{L}^{-1}$ concentration range of SIN-1 and Asc $+\mathrm{NaNO}_{2}$ and did not measure the concentration of $\mathrm{NO}$ released by $\mathrm{SIN}-1$ or $\mathrm{Asc}+\mathrm{NaNO}_{2}$ in rice leaves. We do not know the exact concentration of NO inside the rice leaf tissue. It is possible that the concentration of $\mathrm{NO}$ released by $\mathrm{SIN}-1$ or Asc $+\mathrm{NaNO}_{2}$ is high enough to scavenge free radicals produced by $P Q$, but not sufficient to inhibit the activities of heme-containing enzymes.

In rice leaves, involvement of active oxygen species in water stress-, methyl jasmonate-, excess $\mathrm{Cu}$-, and excess $\mathrm{Cd}$ - promoted senescence has been demonstrated (Hung and Kao 1998, Chen and Kao 1999, Lin and Kao 2000, Chien et al. 2001). Work is under way to determine whether NO counteracts this promotion of senescence in rice leaves. Preliminary results show that the promotion of rice leaf senescence caused by polyethylene glycol, which induces lipid peroxidation, can be counteracted by NO-releasing compounds, but that caused by sorbitol, which has no effect on lipid peroxidation, cannot be counteracted by NO-releasing compounds (unpublished data).

In conclusion, the results presented in this paper suggest that reduction of $P Q$ toxicity by NO in rice leaves is most likely mediated through increase in antioxidative enzyme activities and decrease in lipid peroxidation.

Acknowledgements. This work was supported by grant NSC 902313-B-002-267 from the National Science Council of the Republic of China. 


\section{References}

Beligni MV, Lamattina L (1999a) Nitric oxide counteracts cytotoxic processes mediated by reactive oxygen species in plant tissues. Planta 208: 337-344

Beligni MV, Lamattina L (1999b) Nitric oxide protects against cellular damage produced by methyl viologen herbicides in potato plants. Nitric Oxide 3: 199-208

Benavides MP, Gallego SM, Comba ME, Tomaro ML (2000) Relationship between polyamines and paraquat toxicity in sunflower leaf discs. Plant Growth Regul 31: 215-224

Bradford MM (1976) A rapid and sensitive method for the quantitation of microgram quantities of protein utilizing the principle of proteindye binding. Anal Biochem 72: 248-254

Calderbank A (1968) The bipyridylium herbicides. Adv Pest Cont Res 8: 127-235

Cha LS, McRae DG, Thompson JE (1982) Light-dependence of paraquat-initiated membrane deterioration in bean plants. Evidence for the involvement of superoxide. Physiol Plant 56: 492-499

Chang CJ, Kao CH (1995) Paraquat-induced chlorophyll loss in rice leaves: Evidence for the involvement of light and photosynthetic electron transport. Chinese Agron J 5: 287-293

Chang CJ, Kao CH (1997a) Paraquat toxicity is reduced by metal chelators in rice leaves. Physiol Plant 101: 471-476

Chang CJ, Kao CH (1997b) Paraquat toxicity is reduced by polyamines in rice leaves. Plant Growth Regul 22: 163-168

Chen L-M, Kao CH (1999) Effect of excess copper on rice leaves: evidence for involvement of lipid peroxidation. Bot Bull Acad Sin 40: 283-287

Chien H-F, Wang J-W, Lin CC, Kao CH (2001) Cadmium toxicity of rice leaves is mediated through lipid peroxidation. Plant Growth Regul (in press)

Clark D, Durner J, Navarre DA, Klessig DF (2000) Nitric oxide inhibition of tobacco catalase and ascorbate peroxidase. Mol PlantMicrobe Interact 13: 1380-1384

d'Ischia M, Palumbo A, Buzzo F (2000) Interactions of nitric oxide with lipid peroxidation products under aerobic conditions: Inhibitory effects on the formation of malondialdehyde and related thiobarbituric acid-reactive substances. Nitric Oxide 4: 4-14

Delledonne M, Xia Y, Dixon RA, Lamb C (1998) Nitric oxide functions as a signal in plant disease resistance. Nature 394: 585-588

Drolet G, Dumbroff EB, Legge RL, Thompson JE (1986) Radical scavenging properties of polyamines. Phytochemistry $25: 367-371$

Durner J, Wendehenne D, Klessig DF (1998) Defense gene induction in tobacco by nitric oxide, cyclic GMP, and cyclic ADP-ribose. Proc Natl Acad Sci USA 95: 10328-10333

Farrington JA, Ebert M, Land EJ, Fletcher K (1973) Bipyridylium quaternary salts and related compounds. V. Pulse radiolysis studies of the reaction of paraquat radical with oxygen, implication for the mode of action of bipyridyl herbicides. Biochim Biophys Acta 314: 372-381

Ferrer MA, Bacelo AR (1999) Differential effects of nitric oxide on peroxidase and $\mathrm{H}_{2} \mathrm{O}_{2}$ production by the xylem of Zinnia elegans. Plant Cell Environ 22: 891-897

Foster JG, Hess JL (1980) Responses of superoxide dismutase and glutathione reductase activities in cotton leaf tissue exposed to an atmosphere enriched in oxygen. Plant Physiol 66: 482-487

Foyer CH, Lopez-Delgado H, Dat JF, Scott IM (1997) Hydrogen peroxide- and glutathione-associated mechanism of acclimatory stress tolerance and signaling. Physiol Plant 100: 241-254
Goss SPA, Hogg N, Kalyanaraman B (1997) The effect of nitric oxide release rates on the oxidation of human low density lipoprotein. $J$ Biol Chem 272: 21647-21653

Gutteridge JMC, Rowley DA, Halliwell B (1981) Superoxide-dependent formation of hydroxyl radicals in the presence of iron salts. Biochem J 199: 263-265

Heath RL, Packer L (1968) Photoperoxidation in isolated chloroplasts. I. Kinetics and stoichiometry of fatty acid peroxidation. Arch Biochem Biophys 125: 189-198

Hung KT, Kao CH (1998) Involvement of lipid peroxidation in methyl jasmonate-promoted senescence in detached rice leaves. Plant Growth Regul 24: 17-21

Kato M, Shimizu S (1987) Chlorophyll metabolism in higher plants. VII. Chlorophyll degradation in higher plants. VII. Chlorophyll degradation in senescing tobacco leaves: Phenolic-dependent peroxidative degradation. Can J Bot 65: 729-735

Klessig DF, Durner J, Noad R, Navarre DA, Wendehenne D, Kumar D, Zhou JM, Shah J, Zhand S, Kachroo P, Trifa Y, Pontier D, Lam E, Silva $H(2000)$ Nitric oxide and salicylic acid signaling in plant defense. Proc Natl Acad Sci USA 97: 8849-8855

Kohen R, Chevion M (1985) Transition metals potentiate paraquat toxicity. Free Radic Res Commun 1: 79-88

Kohen R, Chevion M (1986) Paraquat toxicity is enhanced by iron and reduced by desferrioxamine in laboratory mice. Biochem Pharmacol 34: 1841-1843

Kumar D, Klessig DF (2000) Differential induction of tobacco MAP kinases by the defense signals nitric oxide, salicylic acid, ethylene, and jasmonic acid. Mol Plant-Microbe Interact 13: 347-351

Laxalt AM, Beligni MV, Lamattina L (1997) Nitric oxide preserves the level of chlorophyll in potato leaves infected by Phytophthora infestans. Eur J Plant Pathol 103: 643-651

Leshem YY, Haramaty E (1996) Plant aging: the emission of NO and ethylene and effect of NO-releasing compounds on growth of pea (Pisum sativum) foliage. J Plant Physiol 148: 258-263

Leshem YY, Wills RBH, Ku VV-V (1998) Evidence for the function of the free radical gas - nitric oxide (NO) - as an endogenous maturation and senescence regulating factor in higher plants. Plant Physiol Biochem 36: 825-833

Lin J-N, Kao CH (2000) Involvement of lipid peroxidation in water stress-promoted senescence of detached rice leaves. Biol Plant 43: 141-145

Lin J-N, Wang J-W, Kao CH (1999) Effect of abscisic acid and water stress on the senescence of detached rice leaves. Biol Plant 42 : 313-316

MacAdam JW, Nelson CJ, Sharp RE (1992) Peroxidase activity in the leaf elongation zone of tall fescue. Plant Physiol 99: 872-878

Mees GC (1960) Experiment on herbicidal action of 1,1-ethylene-1,2dipyridylium dibromide. Ann Appl Biol 48: 601-612

Millar AH, Day DA (1996) Nitric oxide inhibits the cytochrome oxidase but not the alternative oxidase of plant mitochondria. FEBS Lett 398: $155-158$

Nakano Y, Asada K (1981) Hydrogen peroxide is scavenged by ascorbate-specific peroxidase in spinach chloroplasts. Plant Cell Physiol 22: $867-880$

Naqui A, Chance B (1986) Reactive oxygen intermediates in biochemistry. Annu Rev Biochem 55: 127-166

Navarre DA, Wendehenne D, Durner J, Noad R, Klessig DF (2000) Nitric oxide modulates the activity of tobacco aconitase. Plant Physiol 122: 573-582 
Noritake T, Kawakita K, Doke N (1996) Nitric oxide induces phytoalexin accumulation in potato tuber tissues. Plant Cell Physiol 37: 113-116

O'Donnell VB, Chumley PH, Hogg N, Bloodsworth A, Darley-Usmar VM, Freeman BA (1997) Nitric oxide inhibition of lipid peroxidation: kinetics of reaction with lipid peroxyl radicals and comparison with $\alpha$-tocopherol. Biochemistry 36: 15216-15223

Paoletti F, Aldinucci D, Mocali A, Capparini A (1986) A sensitive spectrophotometric method for the determination of superoxide dismutase activity in tissue extracts. Anal Biochem 154: 536-541

Rauhala P, Sziraki I, Chiueh CC (1996) Peroxidation of brain lipids in vitro: Nitric oxide versus hydroxyl radicals. Free Radic Biol Med 21: 391-394

Rees DD, Palmer RM, Hodson HF, Moncada S (1989) A specific inhibitor of nitric oxide formation from L-arginine attenuates endothelium-dependent relaxation. Br J Pharmacol 96: 418-424

Rubbo H, Radi R, Trujillo M, Telleri R, Kalyanaraman B, Barnes S, Kirk M, Freeman BA (1984) Nitric oxide regulation of superoxide and peroxinitrite-dependent lipid peroxidation. J Biol Chem 269: 26066-26075

Sakuma I, Stuehr DJ, Gross SS, Nathan C, Levi R (1988) Identification of arginine as a precursor of endothelium-derived relaxing factor. Proc Natl Acad Sci USA 85: 8664-8667
Sandy MS, Moldeus P, Ross D, Smith MT (1987) Cytotoxicity of the redox cycling compound diquat in isolated hepatocytes: Involvement of hydrogen peroxide and transition metals. Arch Biochem Biophys 259: 29-37

Scherer GFE, Holk A (2000) NO donors mimic and NO inhibitors inhibit cytokinin action in betalaine accumulation in Amoranthus candatus. Plant Growth Regul 32: 345-350

Schmidt HHWH, Walter U (1994) NO at work. Cell 78: 919-925

Sen S, Cheema IR (1995) Nitric oxide synthase and calmodulin immunoreactivity in plant embryonic tissue. Biochem Arch 11: $221-$ 227

Wink DA, Hanbauer I, Krishna MC, DeGraff W, Gamson J, Mitchell JB (1993) Nitric oxide protects against cellular damage and cytotoxicity from reactive oxygen species. Proc Natl Acad Sci USA 90: 9813-9817

Wintermans JFGM, De Mots A (1965) Spectrophotometric characteristics of chlorophylls $a$ and $b$ and their pheiphytins in ethanol. Biochim Biophys Acta 109: 448-453

Zer H, Peleg I, Chevion M (1994) The protective effect of desferrioxamine on paraquat-treated pea (Pisum sativum). Physiol Plant 92: $437-442$ 